\title{
Biliary stents: models and advancements
}

\author{
Mehmet Ali Kosekli \\ Department of Gastroenterology, Bolu Abant Izzet Baysal University, School of Medicine, Bolu, Turkey
}

\section{ABSTRACT}

Obesity and sedentary lifestyle increase the formation of stones in the biliary tract. Choledochal stent placement with endoscopic intervention in cases of choledochal stones and bile leakage has been a common procedure in gastroenterology practice in recent years. Intervention for post-op biliary strictures is increasing in parallel with the number of liver transplantations. Stent placement procedures for palliation of primary or metastatic malignant processes of the biliary tract also contribute to the comfort of life of patients. In this article, brief information about the stents used in the biliary system is presented.

Key words: Biliary drainage, plastic stent, metallic stent, jaundice, cholestasis.

Mehmet Ali Kosekli, M.D., Assist. Prof., Bolu Abant Izzet Baysal University, School of Medicine, Department of Gastroenterology, Bolu, Turkey

E-mail: kosekli@gmail.com

Received: 2021-09-12 / Revisions: 2021-10-01

Accepted: 2021-10-05 / Published online: 2021-11-01

\section{Introduction}

The common bile duct is responsible of flow of the bile that produced in the liver to the duodenum. Jaundice occurs when bile cannot flow into the duodenum due to stasis or obstruction. Stent placement in the common bile duct provides palliative or permanent treatment in addition to treatment for the underlying etiology in patients with obstructive jaundice.

The process of placing lumen tubes in the bile ducts in order to eliminate bile stasis in the biliary tree is called stenting. Failure to resolve bile stasis carries the risk of hepatocellular insufficiency, cholangitis and biliary cirrhosis. Techniques such as Whipple operation or hepaticojejunostomy, choledochojejunostomy cholecystojejunostomy have been used in the past to overcome biliary obstruction. In parallel with the advances in endoscopic interventions, biliary stenting has taken the first place in eliminating biliary stasis, instead of surgical techniques.

Stents are inserted by endoscopic retrograde cholangiopancreatography (ERCP) by passing through the working channel of the duodenoscope and their removal is with the same method. In cases where the endoscopic method cannot be used, internal or external biliary drainage stents can be inserted externally with the percutaneous transhepatic cholangiography method [1].

Lumen tubes placed in the bile ducts are classified as plastic or metal stents according to the material they are manufactured from.

\section{Plastic biliary stents}

These stents are produced in different diameters, lengths and shapes from polyurethane, polyethylene and their mixtures of plastic materials. Stent diameters are expressed in french (Fr) corresponding to $1 / 3$ of centimeter. Plastic stents can be 3-12 Fr in diameter and $1-25 \mathrm{~cm}$ in length. They are 
manufactured as straight at both ends (Amsterdam type, Figure 1), curved at both

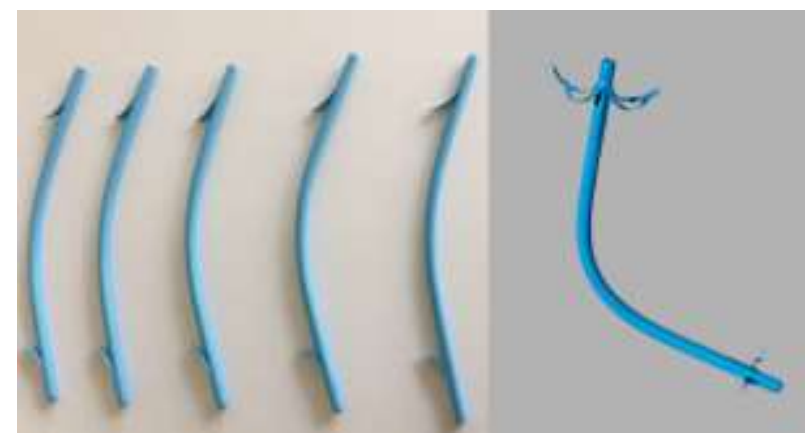

Figure 1. Plastic biliary stent (Amsterdam type).

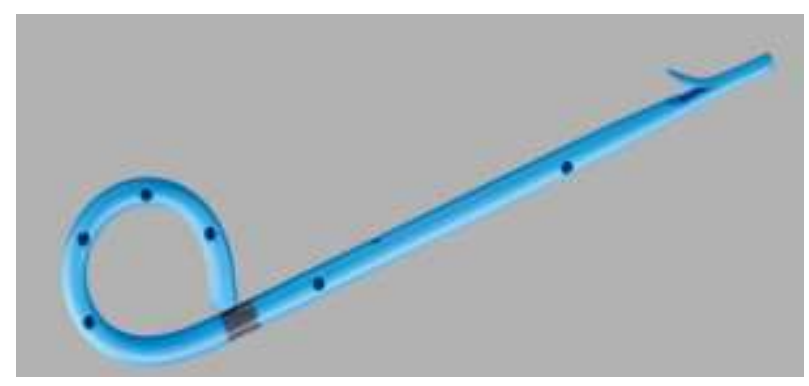

Figure 2. Plastic pigtail biliary stent.

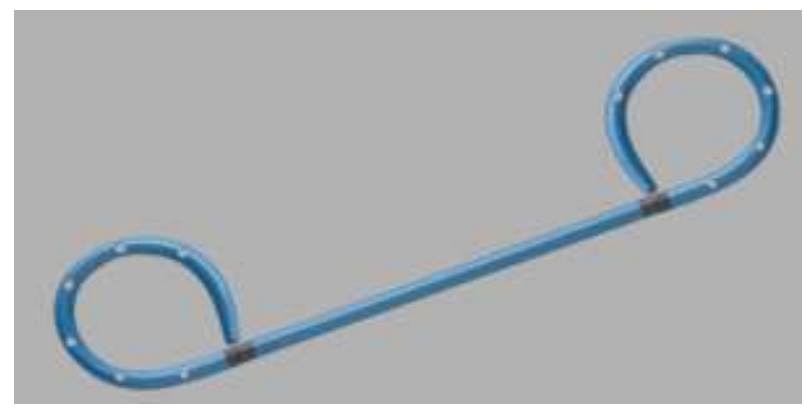

Figure 3. Plastic double pigtail biliary stent.

ends (double pigtail, Figure 2) or as a straight end and pigtail at one end, depending on the place and purpose of use (Figure 3). It has single or multiple flaps at both ends to prevent migration from the lumen.

In patients with gallbladder stones or biliary sludge associated with choledoc stones, plastic stenting is performed on difficult/large/multiple choledoc stones that cannot be completely removed by ERCP after the choledoc stones are removed. In patients with benign biliary stenosis, stenting is performed to maintain the lumen patency after dilation. In addition, plastic stenting suitable for the diameter of the common bile duct is applied to patients with post-op biliary leakage. Stent is applied after removal of ascaris lumbricoides and fasciola hepatica parasites that rarely cause biliary obstruction. The use of plastic stents is limited in biliary strictures secondary to malignant etiology.

Plastic stents can also be placed in the pancreatic duct. The most common indications for pancreatic stenting include; pancreatitis prophylaxis after ERCP procedure, chronic obstructive pancreatitis and congenital variation of the pancreatic duct. Pancreatic stents are used in the canal with flat ends, relatively smaller diameters and short lengths. The most common complication in patients with plastic stent placement is stent migration and obstruction. Less frequently, it may cause pancreatitis, cholangitis, cholecystitis, and intestinal perforation [2].

\section{Metallic stents}

Self-expanding metal stent (SEMS) are reduced in diameter to pass through the working channel of the duodenoscope and reach a certain lumen opening when released. They are generally made of nitinol. Nitinol, an alloy of nickel and titanium, is a tissue-lumen compatible radioopaque material. In addition, steel and nitinolcoated platinum (platinol) are also used in stent construction. They are primarily preferred in malignant diseases of the biliary tree. Metallic stenting is performed in the palliation of jaundice secondary to cholangiocarcinoma, gallbladder, pancreas, ampulla of water, liver cancer and metastatic biliary tract tumors [3, 4]. They promise a wider and longer lumen opening compared to plastic stents [5]. 
Post-operative biliary strictures are cases where both types of stents are used alone or in combination. The use of stents in the treatment of strictural complications after liver transplantation has increased in parallel with the number of transplantations in recent years [6].

Metal stents can be of different diameter (6$12 \mathrm{~mm})$, length $(4-12 \mathrm{~cm})$, shape and structure depending on the localization and stenting indication. Hook and cross, hand woven were produced in different architectural structures in order to expand and provide lumen opening. There are metal stents with partial or full coverage (Figure 5) as well as uncovered (Figure 4).

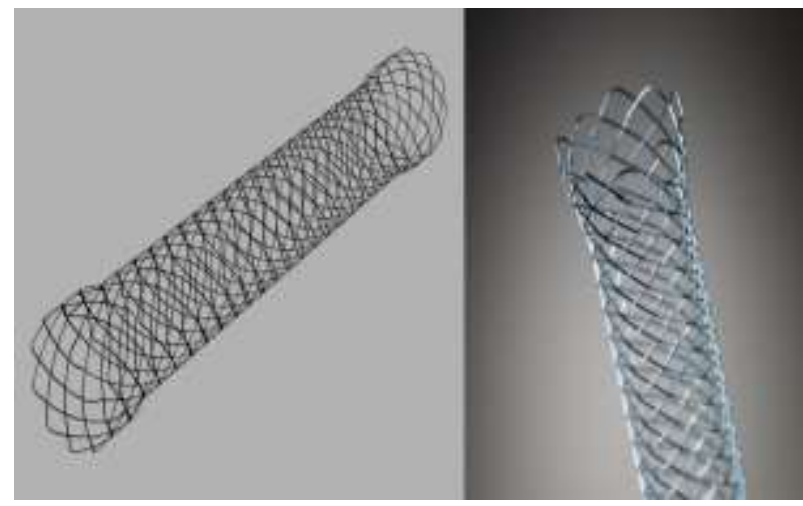

Figure 4. Uncovered self-expandable metallic stent.

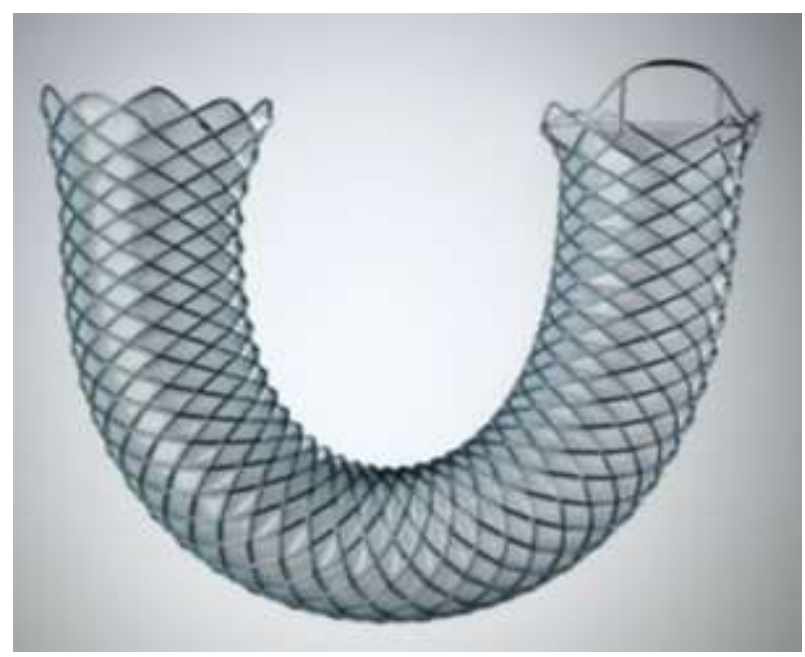

Figure 5. Full covered self-expandable metallic stent.
Stent models covered with silicon material fully or partially are preferred in order to prevent tumor growth in malignant processes. Polyether polyurethane,

polyurethane, polytetrafluoroethylene fluorinated ethylene propylene or polycaprolactone materials are also used as metal stent covering material. There are publications stating that there is no difference between coated metal stents and uncoated metal stents in terms of luminal patency and occlusion [7]. Covered metal stents are easier to remove when needed than uncapped ones, unfortunately, they are more likely to migrate than uncapped stents.

Metallic stents end slightly widened to prevent migration (dumbbell appearance). Y-shaped types are also available to be placed in the intrahepatic bifurcation area. Metallic stents are incomparably more expensive (50-60 times) than plastic stents. It is recommended for patients with a life expectancy longer than 4-5 months [8]. In addition, it is used in selected cases because the risks of cholangitis, occlusion and re-endoscopic intervention are more advantageous than plastic stents [9]. Occlusion due to migration and tumor ingrowth are the main disadvantages of metallic stents. Luminal occlusions can be temporarily overcome by placing another stent with a narrower diameter inside the stent.

While bile sludge, bile stasis, contact of bile with a foreign surface and bacteria facilitate stent lumen obstruction [10-12], coating the inner lumen with perfluoroalkoxyl or a different material and adding an anti-reflux valve mechanism may delay the occlusion of the stents [13]. Silver coating of metallic stents may prolong the luminal opening [14]. Antibiotic-containing stents and biodegradable stents are stents produced as a result of different searches [15]. Magnetic stents are experimental stents that are easily removed without the need 
for endoscopy by advancing outside the body. Stents that release chemotherapeutic or radioactive $\mathrm{I}^{125}$ may contribute to the treatment of the underlying disease in cases of malignancy, together with existing chemotherapy drugs $[16,17]$.

\section{Conclusion}

Stents contribute to palliation in hepatobiliary malignancies, including those without surgical intervention. With the developing endoscopic techniques, more stenting options will emerge, which will force developments in stenting.

Acknowledge: All figures were downloaded from https://www.cookmedical.eu/products.

Funding: The author(s) received no financial support for the research, authorship, and/or publication of this article.

Conflict of Interest: The authors declare that they have no conflict of interest.

Ethical statement: Since this research is a review study, no ethics committee decision was required.

\section{Open Access Statement}

This is an open access journal which means that all content is freely available without charge to the user or his/her institution under the terms of the Creative Commons Attribution NonCommercial License

(http://creativecommons.org/licenses/bync/4.0). Users are allowed to read, download, copy, distribute, print, search, or link to the full texts of the articles, without asking prior permission from the publisher or the author.

Copyright (c) 2021: Author (s).

\section{References}

[1]Teoh AY, Dhir V, Kida M, et al. Consensus guidelines on the optimal management in interventional EUS procedures: results from the Asian EUS group RAND/UCLA expert panel. Gut. 2018;67(7):1209-28.
[2]Lee HW, Moon JH, Choi HJ, et al. Modified fully covered self-expandable metal stent versus plastic stent for preoperative biliary drainage in patients with resectable malignant biliary obstruction. Endoscopy. 2018;50(04):OP122.

[3]Beyna T, Neuhaus H. Self-expandable metal stents in malignant biliary obstruction: Back to the roots with uncovered stents as the "new" standard? Gastrointest Endosc. 2018;87(4):1071-3.

[4]DeOliveira ML, Cunningham SC, Cameron JL, et al. Cholangiocarcinoma: thirty-oneyear experience with 564 patients at a single institution. Ann Surg. 2007;245(5):755-62.

[5]Zhang X, Wang X, Wang L, et al. Effect of covered self-expanding metal stents compared with multiple plastic stents on benign biliary stricture: A meta-analysis. Medicine. 2018; 97(36):e12039.

[6]Rao HB, Prakash A, Sudhindran S, et al. Biliary strictures complicating living donor liver transplantation: problems, novel insights and solutions. World $\mathrm{J}$ Gastroenterol. 2018;24(19):2061-72.

[7]Yang MJ, Kim JH, Yoo BM, et al. Partially covered versus uncovered self-expandable nitinol stents with anti-migration properties for the palliation of malignant distal biliary obstruction: a randomized controlled trial. Scand J Gastroenterol. 2015;50(12):1490-9.

[8]Fukasawa M, Takano S, Shindo H, et al. Endoscopic biliary stenting for unresectable malignant hilar obstruction. Clin J Gastroenterol. 2017;10(6):485-90.

[9]Isayama H, Yasuda I, Ryozawa S, et al. Results of a Japanese multicenter, randomized trial of endoscopic stenting for non-resectable pancreatic head cancer (JMtest): covered Wallstent versus DoubleLayer stent. Dig Endosc. 2011;23(4):310-15. 
[10] Gwon DI, Lee SS, Kim E-Y. Cefotaximeeluting covered self-expandable stents in a canine biliary model: scanning electron microscopic study of biofilm formation. Acta Radiol. 2012;53(10):1127-32.

[11] Vaishnavi C, Samanta J, Kochhar R. Characterization of biofilms in biliary stents and potential factors involved in occlusion. World J Gastroenterol. 2018;24(1):112.

[12]Lee TH, Jang BS, Jung MK, et al. Fabrication of a silver particle-integrated silicone polymer-covered metal stent against sludge and biofilm formation and stentinduced tissue inflammation. Sci Rep. 2016;6(1):1-11.

[13] Yang F, Ren Z, Chai Q, et al. A novel biliary stent coated with silver nanoparticles prolongs the unobstructed period and survival via anti-bacterial activity. Sci Rep. 2016;6(1):1-11.

[14] Yamabe A, Irisawa A, Kunogi Y, et al. Development of biliary stent applying the antibacterial activity of silver: A literature review. Biomed Mater Eng. 2021;32(2):6371.

[15]Fang A, Kim IK, Ukeh I, et al. Percutaneous Management of Benign Biliary Strictures. Semin Intervent Radiol. 2021;38(3):291-99.

[16]Zhu H-D, Guo J-H, Huang M, et al. Irradiation stents vs. conventional metal stents for unresectable malignant biliary obstruction: a multicenter trial. J Hepatol. 2018;68(5):970-77.

[17]He X, Zhu Y, Wang Y, et al. Advances in stent therapy for malignant biliary obstruction. Abdom Radiol. 2021;46(1):351-61. 